\title{
Indicators of Ibero-American scientific production
}

\author{
Maria Helena Palucci Marziale
}

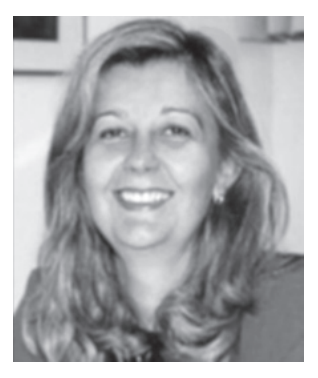

The evaluation of scientific activity is a difficult task due to the way in which knowledge areas mix its objects, theories, methods and techniques to produce new ways of seeing reality; however, the use of qualitative parameters such as evaluation by peers, quantitative indicators of publications, and information technology are the elements used in the evaluation of scientific production. In this direction, the bibliometric indicators are used to evaluate the results of investments in research and the publication of scientific articles, production of patents and answer the questions about the impact of research in the scientific community. Although these indicators may not be considered sufficient demonstration of the degree of scientific development, increasingly, Higher Education Institutions (HEI) and funding agencies which support research and researchers are interested in indicators and international rankings of evaluation.

Thus, in this editorial, it is shown the rankings released recently, which are: the Journal Citation Reports (JCR) produced by ISI Web of Knowledge, the SCImago Journal \& Country Rank (SJR) and the Ibero-American Ranking (SIR) both published by Scopus.

The SIR through bibliometric indicators shows a profile of the scientific activity of Higher Education Institutions based on quantitative data of publications and citations of scientific articles and evidence relevant dimensions of the HEI related to the scientific production. Released in 2011, the SIR analyzed publications of 1369 HEI from 42 Ibero-American countries, published in the Scopus database in the period from 2005 to 2009. The results of this evaluation indicate Spain and Brazil ahead of university research which is developed in the region, being recorded 204,000 scientific documents produced by Spain and 163,000 by Brazil. These countries have the core of most productive universities and their combined production is responsible for two thirds of the total scientific production developed in the Ibero-American HEI. The ranking of the top ten HEI is: University of São Paulo - Brazil, Universidad Nacional Autónoma de Mexico - Mexico, State University of Campinas - Brazil, University of Barcelona - Spain, São Paulo State University Julio de Mesquita Filho - Brazil, Federal University of Rio de Janeiro - Brazil, Universidad Complutense de Madrid - Spain, Universidad Autónoma de Barcelona - Spain, University of Buenos Aires - Argentina and the Universidad Politécnica de Catalunya - Spain. The ranking also shows that Spanish and Brazilian Universities have comparatively high values of quality and ability to publish in prestigious journals, while the visibility of IberoAmerican scientific production, excluding Spain and Brazil, has low levels ${ }^{(1)}$. The Journal Citation Report (JCR) shows the impact of bibliometric indicators of scientific journals by means of a world ranking that spreads the impact factor obtained by the citations of scientific papers published in the ISI in a period from three to five years. Regarding the field of Nursing, the JCR 2010 announced recently the impact factor of 88 Nursing journals; of these $73.9 \%$ were from U.S., 8\% from UK, 6.8\% from Australia, 3.4\% from Brazil, 2.3\% from Switzerland, 2.3\% from South Korea, and $1.1 \%$ from Italy, Netherlands and Colombia. The data show that the Ibero-American Nursing has only four 
journals in the JCR and they are: Revista Latino-Americana de Enfermagem (impact factor 0.856), Revista da Escola de Enfermagem da USP (impact factor 0.455), Acta Paulista de Enfermagem (0.204 impact factor) and Aquichan

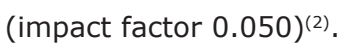

Regarding SCImago Journal \& Country Rank (SJR); it is noted that among the 130 journals in the field of Nursing, only $8.5 \%$ are edited in the region of Ibero-America such as: Revista Latino-Americana de Enfermagem (SJR 0.042 and $\mathrm{H}$ index = 13), Revista da Escola de Enfermagem da USP (SJR 0.034 and $\mathrm{H}$ index $=8$ ), Enfermería Intensiva (SJR 0.032 and $\mathrm{H}$ index = 7), Revista Cubana de Enfermería (SJR 0.025 and $\mathrm{H}$ index = 7), Online Brazilian Journal of Nursing (SJR 0.027 and H index = 5), Revista Brasileira de Enfermagem (SJR 0.029 and H índex = 5), Acta Paulista de Enfermagem (SJR 0.031 and H índex = 5), Revista Gaúcha de Enfermagem (SJR 0.027 and H índex = 4), Enfermería Clinica (SJR 0.028 and $\mathrm{H}$ index =4), Texto \& Contexto Enfermagem (SJR 0.028 and $\mathrm{H}$ index = 2) and Ciencia y Enfermería (SJR 0.027 and $\mathrm{H}$ index $=3)^{(3)}$.

The presented indicators reveal how the production of the Ibero-American Nursing has been evaluated by the scientific community; however, due to the small number of journals in the region indexed in the ISI and Scopus databases, the visibility and impact of the produced knowledge, despite finding in the process of expansion when compared to the last ten years, do not represent the real impact of the production of Ibero-American Nursing added to the improvement of quality of people's life and technologies incorporated in health care and nursing.

\section{References}

1. Scopus. Ranking Iberoamericano SIR 2011. [Internet]. Amsterdam: SCImago Research Group; c2011. [acesso 05 julho 2011]. Disponível em: http://www.scimagolab.com; http://www.scimagoir.com

2. Thomson Reuters. Journal Citation Report. 2010 JCR Science Edition. [Internet]. New York; c2011. [acesso 05 julho 2011]. Disponível em: http://www.isiknowledge.com/JCR

3. Scopus. SCImago Journal \& Country Rank. 2011. [Internet]. Extremadura (ES); C2007-2011. [acesso 05 julho 2011]. Disponível em: http://www.scimagojr.com/journalrank.php?area $=2900 \&$ category $=0 \&$ country $=B R \& y e a r=20$ 10\&order $=$ sjr\&min=0\&min_type $=c d$

Maria Helena Palucci Marziale is Chief Scientific Editor of the Latin American Journal of Nursing, Full Professor of the University of São Paulo at Ribeirão Preto College of Nursing, WHO Collaborating Centre for Nursing Research Development, Brazil, e-mail: marziale@eerp.usp.br. 